\title{
The formative years: medical ethics comes of age
}

\author{
Alastair V Campbell
}

\section{Correspondence to}

Professor Alastair V Campbell, Centre for Biomedical Ethics, National University of Singapore, MD11, 02-04, Clinical Research Centre, 10 Medical Drive, Singapore 117597, Singapore; alastair_v_campbell@nuhs. edu.sg

Received 1 September 2014 Revised 14 October 2014 Accepted 29 October 2014

\section{ABSTRACT}

When the Journal of Medical Ethics first appeared in April 1975, the prospects of success seemed uncertain. There were no scholars specialising in the field, the readership could not be guaranteed, and the medical profession itself seemed, at the very least, ambivalent about a subject thought by many to be the province of doctors alone, to be acquired through an apprenticeship model, and certainly not taught or examined in any formal sense. However, change was afoot, fresh scandals created an awareness that outside help was needed to think through the new challenges facing the profession, and the success of the medical groups revealed a clear way forward through multidisciplinary and critically reflective discussion of the host of emerging ethical and legal issues. In this article the formative years of the journal are recaptured, with a claim that the core principles on which it was founded must endure if it is to continue to 'do good medical ethics' over the next 40 years.

\section{INTRODUCTION}

The first issue of the Journal of Medical Ethics (JME) was published in April 1975. It seemed to be a bold venture at the time, since there was no established discipline or academic department to provide it with the copy that would be required for an international peer reviewed academic journal, nor was it clear whether there would be any significant group of readers and subscribers for such a journal. Would practitioners want to read it, or would it seem too abstract and academic to be of much practical use? And why would other academics in fields, such as law, philosophy and social science, bother with this journal, when they had their own specialist journals to turn to? These were worries at the time of the launch, but, in retrospect, the spectacular success of the journal over the past 40 years seems even more remarkable, when we consider other features of the medical environment at the time. Shotter $e t a l^{1}$ have described the attitude of many of the senior medical figures in the UK towards what they regarded as their province alone.

At that time, it was said that 'ethics could be picked up on a ward-round'; a consultant, declining an invitation to speak (at an event organised by the London Medical Group), wrote that, if these matters were to be discussed at all, which he doubted, they should be discussed 'by consultants, with consultants, and in camera.' This attitude was prevalent in medical education at the time, as is fully described by Stirrat in this issue, ${ }^{2}$ but it was also the received wisdom in professional ethical guidelines, such as those promulgated by the British Medical Association. In the 1974 edition of the British Medical Association's handbook on medical ethics, a paragraph on 'Individual Responsibility' casts some doubt on whether the formulation of rules is of much help in the 'rough and tumble of professional practice' and the writer goes on to quote with approval words to this effect by the Chairman of the Association's Central Ethical Committee in the interwar period, Dr C O Hawthorne.

In the relations of the practitioner to his fellows, while certain established customs and even rules are written and must be written, the principal influence to be cultivated is that of good fellowship. Most men know what is meant by 'cricket' and the spirit of the game. ${ }^{3}$

In this atmosphere of a 'men only' professional club (even although women had begun to qualify as doctors more than 100 years previously!) how very extraordinary it was that a journal dealing with medical ethics could be launched with an explicitly multidisciplinary and critical approach-and, to boot, with an editor (the author of this article), who was not a doctor, but a philosopher and theologian, with no medical experience whatsoever! However, such clubbish attitudes were already dying out in the 1970 s due to dramatic changes in medicine and in society at large. The changes in medical ethics were also catalysed by the evident success of the London Medical Group and similar groups in other UK medical schools. ${ }^{1}$ Very senior figures in medicine were looking for a new openness and honesty in discussions of the dilemmas they faced in practice, and this was fuelled by a demand from their trainees and students that there had to be more to medical ethics than the pronouncements of a few wise old men. The winds of change were blowing through the dusty corridors of medical privilege.

\section{THE WINDS OF CHANGE}

In the period after World War II an air of moral complacency still pervaded the medical profession. Of course, the revelations of medical atrocities in the Nazi concentration camps created a major shock, but these criminal actions seemed to have been dealt with by the Nuremberg trials, with steps taken to avoid them in the future by the founding of the World Medical Association (WMA) and its promulgation of the Geneva Convention Code of Medical Ethics (an updated version of the Hippocratic Oath). The events in the holocaust could thus be seen as the aberrant actions of a few doctors under the sway of a totalitarian regime. Surely, it was felt, most doctors have only the health and welfare of their patients in mind, and would never use them as guinea pigs in medical experiments. However, this illusion was shattered by the writings of Pappworth in the UK and Beecher in the USA. ${ }^{45}$ Numerous unethical clinical trials were exposed, and, later, even worse examples 
were revealed, including the Tuskegee Syphilis Study, which entailed the deliberate withholding of a known effective treatment from a group of poor African-Americans. All this led to an awakening of awareness that doctors and scientists could not be relied upon to know what was 'cricket', and that medical research and medical practice needed critical scrutiny by those outside of the profession as well as by those within it. Out of this new awareness the WMA's Declaration of Helsinki was first formulated and continues to be revised to the present day. These events had a profound effect on American medicine in particular, and led to the publication of the Belmont Report in 1978, which produced new federal regulations on research ethics and governance. Also in the USA, an awareness of the whole new range of ethical dilemmas in medicine and the health sciences led to the setting up in 1969 of the first academic centre in medical ethics by a doctor, Will Gaylin, and a philosopher, Daniel Callahan. In 1971 the centre they established began publishing the first specialised journal in the field, the Hastings Center Report. Thus by the mid-1970s, when the Journal of Medical Ethics was founded, there could be little doubt that a more radical approach to ethics was needed than the traditional reliance on medical self-regulation. This realisation was given a still greater impetus by radical critiques of the medical profession and of the rapidly expanding healthcare industry by writers like Freidson, ${ }^{6}$ Illich $^{7}$ and (later in the field) Kennedy. ${ }^{8}$ Illich's highly influential book, Medical Nemesis, was published shortly before the journal first appeared, and his paper entitled 'The medicalisation of life' (originally delivered to a London Medical Group Conference) was published in the journal's second issue. ${ }^{9}$ The time was ripe for a journal that would recognise the radical changes in medical ethics, while still keeping in touch with the clinical dilemmas doctors faced. Medical ethics had come of age, but, in its newly found adulthood, it had to respect its medical parentage. How was this to be achieved?

\section{ASPIRATIONS AND COMMITMENTS}

The editorial of the first issue of the journal made a clear statement of its aim. The aim of the Journal of Medical Ethics is to provide a forum for the reasoned discussion of moral issues arising from the provision of medical care. It will hold no brief for one professional, political or religious viewpoint. ${ }^{10}$ These fundamental commitments to non-partisanship and reasoned discussion echoed the philosophy of the medical groups, of which the journal was an offspring. Medical ethics can be highly controversial, and there are many strongly held moral positions, frequently supported by religious beliefs. So perhaps it was particularly important to stress this point when the first editor was a theologian as well as a philosopher. It was essential to assure readers that there was no hidden agenda, no crypto-evangelisation, and that all reasonably defended viewpoints would be given equal consideration and respect. However, another key aspect of this statement is that it also distances itself from professional viewpoints, in this case, mainly from the potentially narrow viewpoint of some members of the medical profession. As we have seen, the field had, up to this point, been subject to professional capture; consultants speaking only to consultants-not an area for junior doctors, let alone medical students or allied professionals, and far less patients, to venture into! Yet, while not buying into this paternalist exclusiveness, the journal was committed to keeping an emphasis on 'the provision of medical care'. It did not broaden its scope by adopting 'bioethics' or 'healthcare ethics' as its main focus. Nevertheless, the articles published from the first issue onwards ranged much more widely than what has been called the 'sacred dyad' of the doctor-patient relationship. This was achieved through a varied membership of the editorial board and through the inclusion from the first volume onwards of a broad spectrum of non-medical authors (including such well known lay advocates as the journalist, Katharine Whitehorn).

\section{THE EDITORIAL BOARD}

The first editorial board was marked by the involvement of several well known figures from the medical and legal scene in the UK. In addition to two very senior medical doctors as consulting editors, Professor Charles Fletcher and Professor Archie Duncan, it had as its chairman a surgeon, Professor R B Welbourn, and two highly influential figures in new developments in medicine, Professor Roy Calne, a pioneer in renal transplant surgery, and Dr Cecily Saunders, the founder of the Hospice movement. Other medical specialties were strongly represented, including general practice and psychiatry. At the same time there was a powerful legal input, with a Lord of Appeal (Lord Kilbrandon) on the Board from the outset, and later, Professor Ian Kennedy, the initiator in King's College, London of the first qualification in medical law and ethics in the UK. Another notable early development was the joint publication agreement entered into with the British Medical Journal, resulting in the deputy editor of that journal joining the Board and creating a powerful link to the whole world of international medical publishing. However, while the medical and legal presence was essential, the journal was also fully multidisciplinary. As the first editorial put it, the editors will 'call on the resources of the disciplines of law, philosophy and theology, as well as on the whole range of medical and paramedical specialties' ${ }^{11}$ This commitment is clear in the Board membership, with no less than three theologians (Catholic, Anglican and Presbyterian) serving from early on, plus a senior nurse, two professors of philosophy and a professor of sociology.

\section{COLUMNS AND FEATURES}

To fulfil its role as a multidisciplinary resource, the journal also had to contain more than only academic papers, whether these were commissioned (very common at the beginning of the journal's existence) or unsolicited. The potential readership needed other features to help them see the relevance and attractiveness of ethics. Various likely needs and interests were identified, and these led to two standard features of every issue in the early years of the journal: Case Conference and Analysis.

Case Conference was designed to entice busy clinicians into reading the journal by offering multidisciplinary comment on critical cases that would be close to every doctor's everyday experience. It was invented, designed and edited by Roger Higgs, who became a Professor of General Practice and who had been editor of the predecessor of the JME, Documentation in Medical Ethics, a collection of cyclostyled articles of potential interest to doctors who had as medical students developed their involvement in medical ethics in Ted Shotter's Medical Groups. The Case Conference series was marked by striking and imaginative titles and by the richness and variety of the commentaries on the case.

The second regular feature was Analysis. This was designed to meet a different need: a clear introduction to the basic concepts and theories of moral philosophy, at a readable length, but without dumbing down. A remarkable range of concepts was covered over the years, described in accessible language by several well known philosophers, including Anthony Flew, Dorothy Emmett, Robin Downie, Ronald Hepburn, Raymond Plant and Harry Lesser. The series finally ended, when it seemed that all the basics had been covered, but what was remarkable was the enthusiastic participation of academic 
philosophers, keen to keep the fledgling subject of medical ethics honest in its use of philosophical terminology. As the journal matured, it became clear that other columns were needed to keep the readership up to date. A book review section was, of course, mandatory, but there was also the need to report on the rapidly evolving field of medical ethics in Britain and elsewhere. British readers were briefed on happenings in Parliament in Tony Smith's The Parliamentary Scene, and this was soon followed by two international columns, Report from America by Bernard Towers and Letter from Australia by Anthony Moore. Finally, the journal had a clear responsibility to support the emerging awareness that medical education needed to have a serious commitment to teaching medical ethics and law as core elements of the curriculum, not merely as optional extras. Articles were commissioned from a wide range of medical schools and countries. Over the first 6 years of publication (1975-1980) reports on teaching came from Germany, Ireland, Netherlands (Maastricht and Nijmegen), the UK (Edinburgh, Nottingham and Southampton), the USA and Yugoslavia. This series has continued, but, in addition, the journal has played a key role in the development of core curricula in medical ethics and law, with the aim of more consistency across different schools. ${ }^{12} 13$

\section{PERENNIAL TOPICS}

The range of topics covered in the first 6 years of the journal, seems remarkably similar to those debated today. They included issues at the beginning of life (abortion, new birth technology, treatment of severely handicapped infants) and at the end of life (pain control, palliative care, euthanasia, brain death). There was also the beginning of debates about priorities in healthcare and rationing decisions. On the other hand, the dramatic social changes of the 1960s obviously had a powerful influence. The year 1967 was particularly notable in Britain, since homosexuality was finally decriminalised, 10 years after that had been recommended by the Wolfenden Report; ${ }^{14}$ and termination of pregnancy for therapeutic reasons was made legal that same year. One can see the aftermath of this in the attention to these issues in the journal. Another event in 1967, the first successful heart transplant by Christian Barnard, stimulated a discussion about donations for transplant and definitions of death. The political ferment of the 1970s is reflected in a lively debate about whether healthcare professionals should go on strike. The significance of this range of topics, most of which are still discussed 40 years later, is that they all move medical ethics out of the private sphere of the doctor-patient encounter, and, instead, raise issues of law and social policy that are of interest to everyone. Medical ethics had clearly come of age.

\section{DOING GOOD MEDICAL ETHICS?}

Much has changed since the journal first saw the light of day in April 1975. The remarkable success of the journal is evidenced by the massive increase in articles it receives, leading to a much higher number of issues annually and a constantly rising manuscript refusal rate. 'Impact factors'-an unknown term in 1975 -now loom large on the horizon of the editors, and have a profound effect on the nature of the authorship, as young academics seek to bulk up their curricula vitae in a remorselessly competitive job market. So, in this highly fraught academic climate, what needs to endure from the journal's formative years? It is hardly likely that this article (since it is written by the foundation editor of the journal) can be seen as an objective and dispassionate assessment of the contribution of the early years of the journal's publication. However, whatever the successes and failures of those early years, there are some fundamental principles on which the journal is based that should create a version of medical ethics worthy of the description 'good medical ethics'.

The first of these principles is the avoidance of all forms of special pleading or ideological dominance. From the outset, the journal's founders were especially wary of religious bias, given the strong involvement of three Christian clergymen-Ted Shotter, Alastair Campbell and Kenneth Boyd-in the creation of the journal. Certainly, it would be hard to see any signs of such bias, from the first issue onwards. But religion, Christian or otherwise, is not the only ideology that can try to take over medical ethics. Powerful secular ideologies-notably Consequentialism in its various forms-have had a major influence in contemporary medical ethics, often with the argument that it is the only 'rational' way of doing ethics. This is plainly wrong, given the current richness of ethical theory in modern philosophy. Such ideological claims must be resisted as strongly as attempts at takeover by religion, if we are to have a genuinely 'good' medical ethics. The second foundational principle has to do with the promotion of interdisciplinarity or multidisciplinarity. We have noted such an aim in the first 6 years of the journal. This must be maintained to avoid medical ethics becoming merely a branch of some other discipline-whether it be philosophy, law or social science. At the very least, the disciplines must talk to each other (interdisciplinarity), but, even better they should work together (multidisciplinarity), despite the difficulties of achieving this in a coherent fashion. In particular, good medical ethics can be achieved only when the theorising stays closely in touch with the realities of healthcare. This entails talking to and working with doctors and other healthcare providers. It means engaging with the experiences of the recipients of healthcare and with the policy makers who set the framework for success and failure in healthcare delivery. In this respect, empirical research in medical ethics, while not a panacea, is an essential component of any useful theoretical account of the ethical issues. Given the maintenance of these two foundational principles, I suggest that the journal can stay true to its original commitments, and continue to foster good medical ethics for the next 40 years.

\section{Competing interests None.}

Provenance and peer review Commissioned; internally peer reviewed.

\section{REFERENCES}

1 Shotter $E$, Lloyd $M$, Higgs $R$, et al. Fifty years of medical ethics: from the London Medical Group to the Institute of Medical Ethics. J Med Ethics 2013;39:662-6.

2 Stirrat GM. Reflections on learning and teaching medical ethics in UK medical schools. J Med Ethics 2015:41:8-11.

3 British Medical Association. Medical Ethics. London: British Medical Association, 1974:12.

4 Pappworth MH. Human guinea pigs: experimentation in man. London: Routledge and Kegan Paul, 1967

5 Beecher HK. Research and the individual. Boston: Little, Brown, 1970.

6 Freidson E. Profession of medicine: a study of the sociology of applied knowledge. London: University of Chicago Press, 1988.

7 Illich I. Medical nemesis. London: Calder \& Boyars, 1974

8 Kennedy I. Reith lectures: the unmasking of medicine. London: George Allen \& Unwin, 1981.

9 Illich I. The medicalization of life. J Med Ethics 1975;1:73-7.

10 Editorial. J Med Ethics 1975;1:1.

11 Editorial. Ibid.

12 Consensus Group of Teachers of Medical Ethics and Law in UK Medical Schools. Teaching medical ethics and law within medical education: a model for the UK core curriculum. J Med Ethics 1998;24:188-92.

13 Stirrat GM, Johnston C, Gillon R, et al. Teaching and learning ethics: medical ethics and law for doctors of tomorrow: the 1998 consensus statement updated. J Med Ethics 2010;36:55-60.

14 Committee on Homosexual Offences and Prostitution. Report of the Committee on Homosexual Offences and Prostitution. London: Her Majesty's Stationery Office, 1957. 